\title{
IDENTIFIKASI SAMPAH ANORGANIK PADA EKOSISTEM MANGROVE DI DESA LESAH KECAMATAN TAGULANDANG KABUPATEN SITARO
}

\author{
(Identification of Inorganic Waste in Mangrove Ecosystem at Lesah Village, Tagulandang \\ Subdistrict, Sitaro Regency)
}

\author{
Stenly J. Loliwu ${ }^{1 *}$, Natalie D. C. Rumampuk ${ }^{1}$, Joshian N.W. Schaduw ${ }^{1}$, Sandra O. Tilaar ${ }^{1}$, \\ Frans Lumoindong ${ }^{1}$, Billy T. Wagey ${ }^{1}$, Ari B. Rondonuwu ${ }^{2}$
}

1. Program Studi IImu Kelautan, Fakultas Perikanan dan IImu Kelautan, Universitas Sam Ratulangi, Manado.

2. Program Studi Manajemen Sumber Daya Perairan, Fakultas Perikanan dan Ilmu Kelautan, Universitas Sam Ratulangi Manado

*e-mail : loliwustenly@gmail.com

\begin{abstract}
Based on the material content, waste is grouped into two types, namely organic waste (waste derived from animal, plant and human parts) and inorganic waste (waste derived from materials such as metal, glass, styrofoam, plastic and rubber). Inorganic waste is one of the coastal pollution problems, yet information about inorganic waste in mangrove ecosystem was relatively low, especially at Lesah Village, Tagulandang Sub district, Sitaro Regency. This study aims to determine the distribution of inorganic waste by type and to analyze the characteristic of inorganic waste based on the amount of size and weight found. The method used in this research is the line transects method at 3 different stations. The results showed that the types of marine debris that found were plastic, rubber, metal, and glass waste and there were 2 characteristics, namely mega-debris and macro-debris. Of the various types of debris obtained, plastic is the most commonly found, 161 items $/ 23.329 \mathrm{~m}^{2}(69.099 \mathrm{Items} / \mathrm{ha})$ with a total weight of $1357.75 \mathrm{gram} / \mathrm{ha}$ and a total size of $1938.93 \mathrm{~cm} / \mathrm{ha}$. Followed by rubber debris as many as 5 items $/ 23.329 \mathrm{~m}^{2}(2.146 \mathrm{items} / \mathrm{ha})$ with a total weight of $159.309 \mathrm{gram} / \mathrm{ha}$ and a total size of $59.871 \mathrm{~cm} / \mathrm{ha}$. Then, glass debris as many as 4 items $/ 23.329 \mathrm{~m}^{2}(1.717 \mathrm{items} / \mathrm{ha})$ with a total weight of $402,159 \mathrm{grams} / \mathrm{ha}$ a total size of $31.030 \mathrm{~cm} / \mathrm{ha}$. Whereas, metal debris is the lowest value found as many as 3 item $/ 23.329 \mathrm{~m}^{2}(1.288$ items $/ \mathrm{ha})$ with a total weight of $67.622 \mathrm{gram} / \mathrm{ha}$ and a total size of $19.528 \mathrm{~cm} / \mathrm{ha}$.
\end{abstract}

Keywords: Inorganic waste, Mangrove Ecosystem, Desa Lesah

\begin{abstract}
Abstrak
Berdasarkan kandungan materinya, sampah dikelompokan menjadi dua jenis, yaitu sampah organik (sampah yang berasal dari bagian hewan, tumbuhan dan manusia) dan sampah anorganik (sampah yang berasal dari bahan seperti logam, kaca, styrofoam, plastik dan karet). Sampah anorganik menjadi salah satu masalah pencemaran pesisir, namun informasi mengenai sampah anorganik di ekosistem mangrove masih relatif sedikit khususnya di Desa Lesah Kecamatan Tagulandang Kabupaten Sitaro. Penelitian ini bertujuan untuk mengetahui sebaran sampah anorganik berdasarkan jenisnya dan menganalisis karakteristik sampah anorganik berdasarkan jumlah ukuran dan beratnya yang ditemukan pada lokasi penelitian. Metode yang digunakan adalah metode line transect dengan 3 stasiun berbeda. Hasil penelitian menunjukkan bahwa jenis sampah laut yang ditemukan pada lokasi penelitian berupa sampah plastik, karet, logam, dan kaca dan terdapat 2 karakteristik yaitu mega-debris dan macro-debris. Dari berbagai semua jenis sampah yang didapatkan, plastik merupakan yang paling banyak dengan jumlah 161 item $/ 23.329 \mathrm{~m}^{2}(69.099 \mathrm{ltem} / \mathrm{Ha})$ dengan bobot berat $1357.75 \mathrm{gram} / \mathrm{ha}$ dan total ukuran $1938.93 \mathrm{~cm} / \mathrm{ha}$. Sampah jenis karet sebanyak 5 item/23.329m2 (2.146 Item/Ha) dengan bobot berat $159.309 \mathrm{gram} / \mathrm{ha}$ dan total ukuran $59.871 \mathrm{~cm} / \mathrm{ha}$. Selanjutnya, sampah jenis kaca sebanyak 4 item/23.329m2 $(1.717 \mathrm{Item} / \mathrm{Ha})$ dengan berat $(402,159$
\end{abstract}


gram $/ \mathrm{ha})$ dan total ukuran $(31.030 \mathrm{~cm} / \mathrm{ha})$. Sampah jenis logam adalah sampah yang nilainya terendah dengan total 3 item $/ 23.329 \mathrm{~m}^{2}(1.288 \mathrm{Item} / \mathrm{Ha})$ dengan bobot berat $(67.622 \mathrm{gram} / \mathrm{ha})$ dan total ukuran $(19.528 \mathrm{~cm} / \mathrm{ha})$.

Kata Kunci: Sampah Anorganik, Ekosistem Mangrove, Desa Lesah

\section{PENDAHULUAN}

Sampah laut adalah salah satu permasalahan yang diakibatkan oleh ulah manusia yang banyak dihadapi oleh banyak kota di seluruh dunia. Timbulnya permasalahan sampah ini, tidak terlepas dari pertumbuhan pesat penduduk yang diikuti dengan pertambahan kebutuhan dan aktifitas manusia sehingga mendorong volume sampah semakin meningkat (Salinding dkk., 2016). Sampah laut, juga disebut sebagai kotoran laut, didefinisikan oleh NOAA (2013) sebagai benda padat persistent, diproduksi atau diproses oleh manusia, secara langsung atau tidak sengaja dibuang atau ditinggalkan di dalam lingkungan laut.

Sampah tersebut secara tidak langsung masuk ke perairan laut melalui sungai, saluran pembuangan air, air limpasan, angin atau secara tak sengaja hilang, termasuk barang-barang yang hilang di laut (perlengkapan penangkapan ikan) dan juga sampah tersebut banyak ditemukan di daerah pantai atau pesisir. Tipe sampah laut yaitu plastik, kain, busa, styrofoam, kaca, keramik, logam, kertas dan karet. Hal ini sangat penting dan menarik untuk diteliti, dikarenakan dampak yang ditimbulkan oleh sampah laut dapat mengancam ekosistem mangrove beserta kehidupan biota yang terdapat di ekosistem tersebut (Mulana, 2016).

$$
\text { Desa Lesah Kecamatan }
$$

Tagulandang Kabupaten Sitaro merupakan daerah dengan berbagai macam aktivitas manusia. Aktivitas-aktivitas tersebut dapat memberikan kontribusi pencemaran berupa sampah pada ekosistem mangrove khususnya sampah anorganik. Komposisi dan kepadatan sampah anorganik pada ekosistem mangrove merupakan informasi kuantitatif dalam menentukan strategi pengelolaan sampah di Desa Lesah Kecamatan Tagulandang Kabupaten Sitaro.

Tujuan penelitian ini adalah Mengetahui sebaran sampah anorganik berdasarkan jenis yang ada di Desa Lesah Kecamatan Tagulandang Kabupaten Sitaro dan Menganalisis karakteristik sampah anorganik berdasarkan jumlah, ukuran dan berat yang ada pada ekositem mangrove di Desa Lesah Kecamatan Tagulandang Kabupaten Sitaro berdasarkan jumlah, ukuran dan berat.

\section{METODE PENELITIAN}

Pengambilan Sampel dilakukan di Desa Lesah Kecamatan Tagulandang Kabupaten Sitaro dengan titik koordinat 2'21'29.24"LU 125²2'12.12"BT pada bulan november 2019. Peta lokasi pengambilan sampel ditampilkan pada Gambar 1 dengan skala peta $1: 250.000$. Adapun alat dan bahan yang digunakan selama penelitian yaitu tali rafia, alat tulis, Global positioning system (GPS), rol meter, kamera, mistar, timbangan dan karung. 

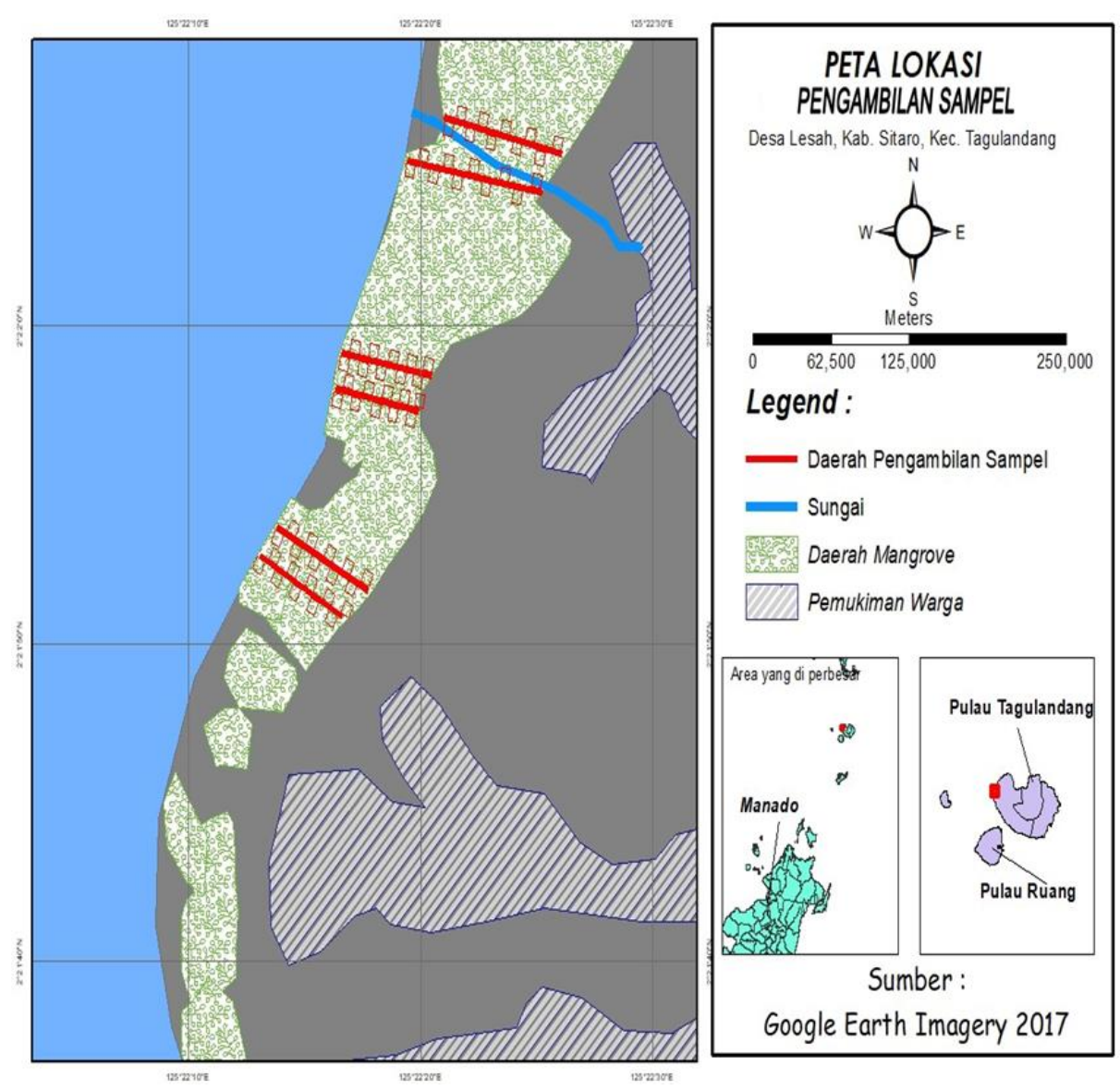

Gambar 1 : Peta Lokasi Penelitian

\section{Teknik Pengambilan Data}

Penelitian dilakukan pada 3 stasiun dengan luas area $23.329 \mathrm{~m}^{2}$. Setiap stasiun terdapat 2 line transect dengan masing-masing memiliki 10 petak/plot pengambilan sampel. Jalur transek pengamatan dimulai dengan arah tegak lurus dari arah laut ke arah darat sepanjang 100 meter. Jarak antar stasiun adalah 50 meter dan jarak antar transek adalah 10 meter, dimana jalur transek tersebut harus mewakili wilayah penelitian. Penarikan line transect dilakukan pada saat air surut.

\section{Analisis Data}

Sampel sampah yang telah dikumpulkan selanjutnya dilakukan pengelompokkan sampel berupa plastik, karet, logam dan kaca. Perhitungan total jumlah, berat dan ukuran sampah perjenis pada tiap stasiun mengikuti persamaan sebagai berikut ini (NOAA, 2013):

Perhitungan yang dilakukan untuk mengetahui nilai total dan nilai rata-rata untuk jumlah sampah setiap jenis

Jn Tot $=$ JnStasiun $1+$ JnStasiun $2+$ JnStasiun 3

$\mathrm{Jnx}=\frac{\mathrm{J} n \text { Stasiun } 1+\mathrm{J} n \text { Stasiun } 2+\mathrm{J} n \text { Stasiun } 3}{\mathrm{X} \text { Stasiun }}$

Perhitungan yang dilakukan untuk mengetahui nilai total dan nilai rata-rata untuk berat sampah setiap jenis

BnTot $=$ BnStasiun $1+$ BnStasiun $2+$ BnStasiun 3

$\mathrm{Bnx}=\frac{\mathrm{B} n \text { Stasiun } 1+\mathrm{B} n \text { Stasiun } 2+\mathrm{B} n \text { Stasiun } 3}{\mathrm{X} \text { Stasiun }}$

Perhitungan yang dilakukan untuk mengetahui nilai total dan nilai rata-rata untuk ukuran sampah setiap jenis 
UnTot $=$ UnStasiun $1+$ UnStasiun $2+$ UnStasiun 3

Keterangan:

Jn Tot $=$ Total jumlah sampah jenis $n$ (buah) $J n \dot{X}=$ Rata-rata jumlah sampah jenis $n$ (buah)

BnTot = Total berat sampah jenis $n$ (gram) $B n \dot{X}=$ Rata-rata berat sampah jenis $n$ (gram)

\section{HASIL DAN PEMBAHASAN}

\section{Sebaran Sampah Anorganik}

Berdasarkan hasil yang didapatkan pada ekosistem mangrove di Desa Lesah, menunjukkan bahwa sebaran sampah anorganik terdiri atas 4 kategori jenis yaitu sampah plastik, karet, logam, kaca dan
Unx $=\frac{\text { Un Stasiun } 1+\text { Un Stasiun } 2+U n \text { Stasiun } 3}{\mathrm{X} \text { Stasiun }}$

UnTot = Total ukuran sampah jenis $n$ (Centi meter)

UnX = Rata-rata ukuran sampah jenis $n$ (Centi meter)

lain-lain berdasarkan NOAA (2013). Kategori sampah tersebut dibedakan lagi berdasarkan bahan penyusun dari sampah yang didapatkan dan dilakukan perhitungan jumlah setiap jenis pada masing-masing stasiun, seperti yang ditampilkan pada Tabel 1 dan Tabel 2.

Tabel 1. Kategori sampah

\begin{tabular}{|c|l|l|}
\hline No. & \multicolumn{1}{|c|}{ Kategori } & \multicolumn{1}{c|}{ Jenis } \\
\hline 1. & Plastik & $\begin{array}{l}\text { Gelas plastik, nilon, tali rafiah,nilon, botol minuman, } \\
\text { bungkus plastik,kresek, karung, bungkus kosmetik alat } \\
\text { mandi, softex, popok, potongan keranjang, Styrofoam. }\end{array}$ \\
\hline 2. & Karet & Sandal jepit, sepatu, tas dan potongan karet \\
\hline 3. & Logam & Kaleng minuman \\
\hline 4. & Kaca & Botol kaca, beling/pecahan kaca. \\
\hline
\end{tabular}

Tabel 2. Jumlah setiap jenis sampah dan rata-rata jumlah sampah jenis $n$ (buah) (JnX) pada masing-masing stasiun

\begin{tabular}{|c|l|c|c|c|c|c|}
\hline \multicolumn{5}{|c|}{ Jumlah Total Sampah } & \multirow{2}{*}{ J $\boldsymbol{n}$ Tot } & \multirow{2}{*}{ J $\boldsymbol{n X}$} \\
\cline { 1 - 4 } No. & Jenis & S1 & S2 & S3 & & \\
\hline 1 & Plastik & 62 & 54 & 45 & 161 & 17.89 \\
\hline 2 & Karet & 3 & 0 & 2 & 5 & 0.56 \\
\hline 3 & Logam & 1 & 1 & 1 & 3 & 0.33 \\
\hline 4 & Kaca & 2 & 2 & 0 & 4 & 0.44 \\
\hline
\end{tabular}




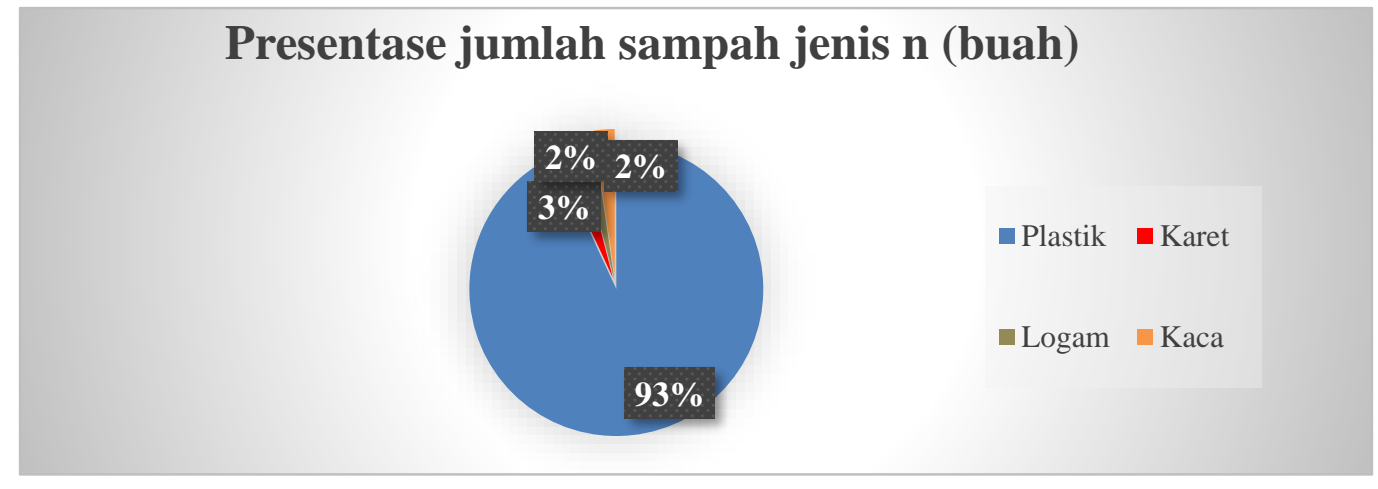

Gambar 2. Diagram pie presentase jumlah sampah anorganik perjenis

Dari berbagai jenis sampah anorganik yang didapatkan yang termuat dalam (Gambar 2) menunjukan bahwa jenis sampah plastik merupakan jenis yang terbanyak kedua adalah karet 5 item dengan nilai rata-rata 0.56 , kaca 4 item dengan nilai rata-rata 0.44 ., dan logam 3 item dengan nilai rata-ratanya 0,33 . Persentase kepadatan sampah anorganik di ekosistem mangrove Desa Lesah menunjukan bahwa jenis sampah plastik merupakan yang tertinggi (93\%), diikuti karet $(3 \%)$, logam $(2 \%)$, dan kaca $(2 \%)$. Hasil penelitian menunjukkan bahwa plastik merupakan sampah dengan presentase paling tinggi tidak hanya di lokasi penelitian. Namun terdapat beberapa penelitian pada lokasi yang berbeda menunjukkan plastik merupakan sampah yang paling banyak ditemukan.

Kahar dkk. (2020) melaporkan sampah plastik merupakan sampah anorganik yang paling banyak ditemukan pada ekosistem mangrove pantai Talawaan Bajo (berdekatan dengan pemukiman warga) yaitu sebesar 162 dengan rata-rata 10,80 . Kondisi yang sama juga dilaporkan pada penelitian Djaguna dkk. (2019) dengan lokasi penelitian di pantai Tongkaina dan Talawaan Bajo. Dimana kepadatan sampah plastik sebesar 481 dengan rata-rata 8,014. Selain itu, pada penelitian Patuwo dkk. (2020) di pantai Tumpaan Desa Tateli juga mendapatkan hasil presentase kepadatan sampah paling banyak ditemukan di ekosistem mangrove Desa Lesah yaitu sebanyak 161 item dengan nilai rata-rata 17.89 , diikuti

plastik yang tertinggi sebesar 228 dengan rata-rata 76 .

Berdasarkan beberapa penelitian tersebut menunjukkan jenis sampah plastik memiliki penyebaran dan keberadaan yang lebih tinggi dibandingkan jenis sampah lainnya. Hal ini juga didukung dengan penelitian yang telah dilakukan oleh NOAA (2016) dimana sampah plastik terdapat diseluruh perairan di dunia.

\section{Karakteristik Ukuran dan Berat Sampah Anorganik}

Berdasarkan ukurannya, Lippiat dkk. (2013) membagi karakteristik sampah laut menjadi 5 kategori yaitu mega-debris ( $>1 \mathrm{~m})$, macro-debris $(>2,5$ $\mathrm{cm}-1 \mathrm{~m})$, meso-debris ( $5 \mathrm{~mm}-2,5 \mathrm{~cm})$, micro-debris $(0,33 \mathrm{~mm}-5,00 \mathrm{~mm})$ dan nano-debris $(<1 \mu \mathrm{m})$. Hasil pengamatan sampel sampah anorganik yang diperoleh di lokasi penelitian termasuk ke dalam 2 karakteristik sampah anorganik yaitu mega-debris dan macrodebris, hasil ini dapat dilihat pada Tabel 3. Dari berbagai jenis sampah yang ditemukan pada tiap stasiun, plastik merupakan jenis yang total ukurannya paling besar yaitu sebesar $4517.70 \mathrm{~cm}$ dengan rata-rata $501.97 \mathrm{~cm}$, diikuti karet dengan nilai total $139.5 \mathrm{~cm}$ dan rata-rata 
$15.50 \mathrm{~cm}$, selanjutnya kaca $72.30 \mathrm{~cm}$ dengan nilai rata-rata $8.03 \mathrm{~cm}$ dan logam $46 \mathrm{~cm}$ dengan nilai rata-rata $5.06 \mathrm{~cm}$. Persentase ukuran sampah anorganik di ekosistem mangrove Desa Lesah (Gambar 3) menunjukan bahwa jenis sampah plasik merupakan yang terbesar (95\%), diikuti karet $(3 \%)$, kaca (1\%), dan logam (1\%).
Total berat sampah perjenis yang didapatkan di 3 stasiun titik pengamatan ditunjukkan pada Tabel 8. Persentase berat sampah tersebut dapat dilihat pada Gambar 4.

Tabel 3. Ukuran sampah anorganik

\begin{tabular}{|c|c|c|c|c|c|}
\hline \multicolumn{4}{|c|}{ Jumlah Ukuran (Cm) Sampah } & \multirow{2}{*}{ Un Tot } & \multirow{2}{*}{ UnX } \\
\hline Jenis & S1 & S2 & S3 & & \\
\hline Plastik & 2945.3 & 882.00 & 690 & 4517.70 & 501.97 \\
\hline Karet & 87 & 0 & 52.5 & 139.5 & 15.50 \\
\hline Logam & 10 & 24 & 11.5 & 46 & 5.06 \\
\hline Kaca & 48.5 & 23.80 & 0 & 72.30 & 8.03 \\
\hline
\end{tabular}

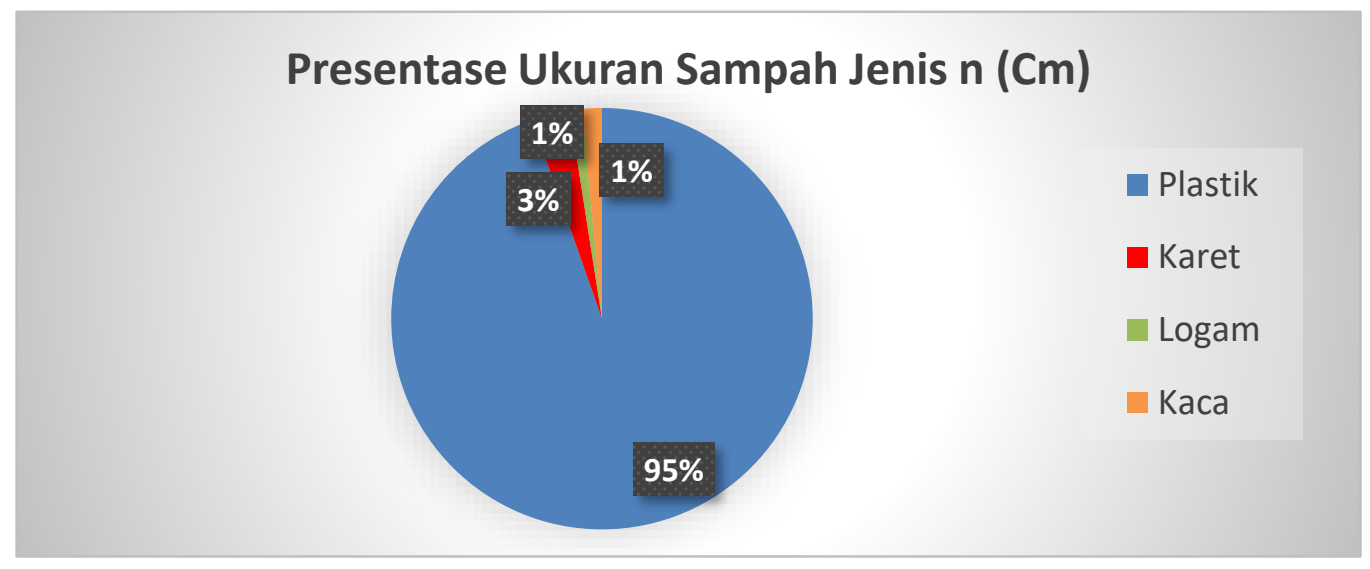

Gambar 3. Diagram pie presentase ukuran sampah jenis

Tabel 4. Berat sampah perjenis

\begin{tabular}{|c|c|c|c|c|c|}
\hline \multicolumn{4}{|c|}{ Jumlah Berat (g) Sampah } & \multirow{2}{*}{ Bn Tot } & \multirow{2}{*}{$B n X$} \\
\hline Jenis & S1 & S2 & S3 & & \\
\hline Plastik & 1413.97 & 972.93 & 777 & 31663.55 & 351.51 \\
\hline Karet & 332.68 & 0 & 38.51 & 371.19 & 41.24 \\
\hline Logam & 115.03 & 26.74 & 15.79 & 157.56 & 17.51 \\
\hline Kaca & 697.02 & 240.01 & 0 & 937.03 & 104.11 \\
\hline
\end{tabular}




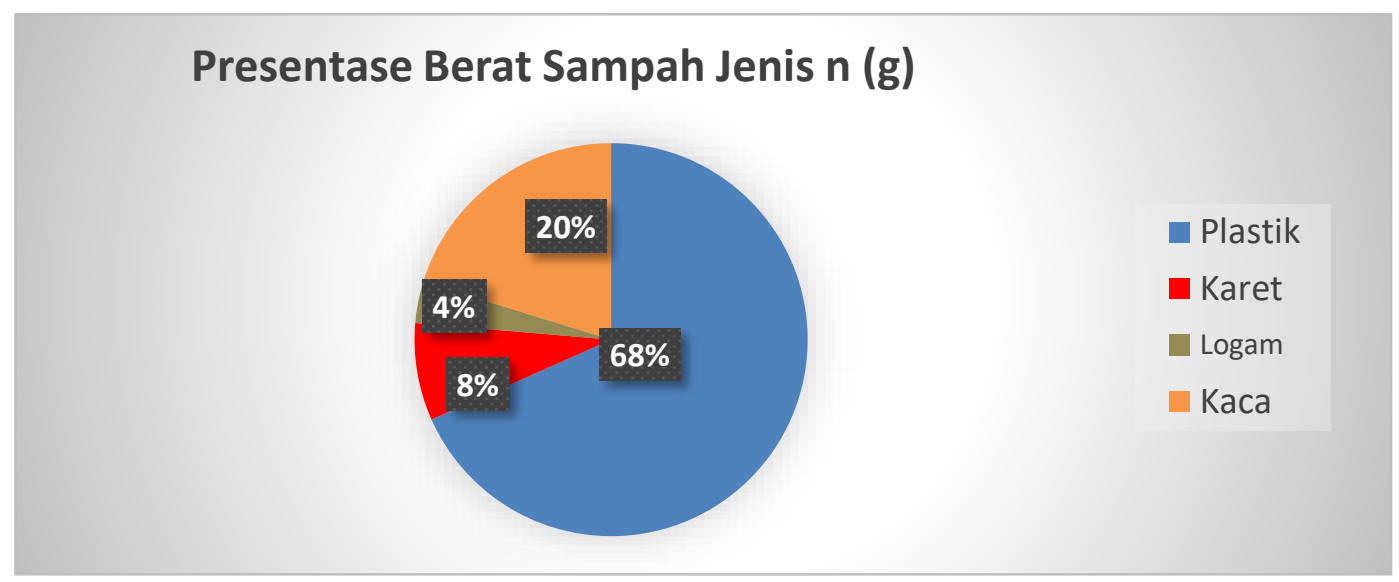

Gambar 4. Diagram pie presentase berat sampah

Berdasarkan hasil yang ditunjukkan pada tabel diatas, nilai bobot berat sampah anorganik yang paling tinggi adalah jenis sampah plastik dengan nilai total 31663.55 $\mathrm{g}$ dan rata-rata berat 351.51 sedangkan yang paling rendah adalah jenis sampah logam dengan nilai total $157.56 \mathrm{~g}$ dan ratarata 17.51. Persentase bobot berat sampah anorganik di ekosistem mangrove Desa Lesah menujukan bahwa jenis sampah plasik merupakan yang terbesar $(68 \%)$, sedangkan bobot yang terendah adalah logam (4\%).

Nilai sampah anorganik yang dihasilkan dalam penelitian ini dengan jelas dapat dilihat pada tabel 9 .

Tabel 9. Total jumlah item,ukuran dan berat sampah anorganik pada luas area ekosistem mangrove Desa Lesah.

\begin{tabular}{|l|c|c|c|c|}
\hline Jenis & $\begin{array}{c}\text { Total jumlah } \\
\text { sampah }\end{array}$ & $\begin{array}{c}\text { Jumlah } \\
\text { Item/ha }\end{array}$ & $\begin{array}{c}\text { Bobot } \\
\text { berat/ha }\end{array}$ & $\begin{array}{c}\text { Total } \\
\text { ukuran/ha }\end{array}$ \\
\hline Plastik & 161 & 690.99 & 1357.75 & 1938.93 \\
\hline Karet & 5 & 2.146 & 159.30 & 598.71 \\
\hline Kaca & 4 & 1.717 & 4021.59 & 310.30 \\
\hline Logam & 3 & 1.288 & 676.22 & 195.28 \\
\hline
\end{tabular}

Secara keseluruhan total jumlah potongan sampah anorganik terbanyak adalah jenis plastik dengan total 161 item/23.329m² $(6.909,9$ Item/Ha) dengan bobot berat $(13.577,5 \mathrm{gram} / \mathrm{Ha})$ dan total ukuran $(19.389,3 \mathrm{~cm} / \mathrm{Ha})$. Sampah jenis karet sebanyak 5 item/23.329m ${ }^{2}(2.146$ Item/ $\mathrm{Ha})$ dengan bobot berat $(1.593$ gram $/ \mathrm{Ha})$ dan total ukuran $(5.987,1$ $\mathrm{cm} / \mathrm{Ha}$ ). Sampah jenis kaca sebanyak 4 item/23.329m2 (1.717 Item/Ha) dengan berat $(4.021,59 \mathrm{gram} / \mathrm{Ha})$ dan total ukuran (3.103 cm/Ha). Sampah jenis logam adalah sampah yang nilainya terendah dengan total 3 item/23.329m ${ }^{2}$ (1.288 Item/Ha) dengan bobot berat (6.762.2 gram/ha) dan total ukuran $(1.952,8 \mathrm{~cm} / \mathrm{ha})$.

Beberapa penelitian yang telah dilaporkan juga menunjukkan nilai rata-rata berat total sampah anorganik tertinggi adalah nilai dari sampah plastik. Penelitian Kahar dkk. (2020) di ekosistem mangrove pantai Talawaan Bajo yang berdekatan dengan pemukiman warga ditemukan nilai rata-rata berat sampah anorganik jenis plastik $1043.84 \mathrm{~g}$. 
Kondisi yang sama terdapat juga di Pantai Tongkaina dan Talawaan Bajo pada penelitian Djaguna, dkk. (2019) didapatkan nilai bobot total yaitu $1433.38 \mathrm{~g}$. Selain itu pada penelitian Patuwo, dkk. (2020) di Pantai Tumpaan Desa Tateli Dua Kecamatan Mandolang Kabupaten Minahasa didapatkan nilai berat total keseluruhan $2062.32 \mathrm{~g}$.

\section{KESIMPULAN DAN SARAN \\ Kesimpulan}

Jenis sampah laut yang pada umumnya ditemukan pada lokasi penelitian berupa sampah plastik, karet, logam, dan kaca. Namun, jenis sampah yang paling dominan adalah sampah plastik, yaitu sebanyak 161 item diikuti karet 5 item, kaca 4 item dan logam 3 item. Dari berbagai jenis sampah yang ditemukan pada tiap stasiun, plastik merupakan jenis yang rata-rata ukurannya paling besar yaitu $501.97 \mathrm{~cm}$ dengan berat $351.51 \mathrm{~g}$ diikuti karet nilai rata-rata $15.50 \mathrm{~cm}$ dengan berat $41.24 \mathrm{~g}$ selanjutnya kaca nilai rata-rata $8.03 \mathrm{~cm}$ dengan berat $104.11 \mathrm{~g}$ dan terakhir logam nilai rata-rata $5.06 \mathrm{~cm}$. dengan

\section{DAFTAR PUSTAKA}

Djaguna, A., W.E. Pelle., J.N.W. Schaduw., H.W.K. Mangengkey., N.D.C. Rumampuk., E. L. A. Ngangi. 2019. Identifikasi Sampah Laut Di Pantai Tongkaina dan Talawaan Bajo. Jurnal Pesisir dan Laut Tropis. Fakultas Perikanan dan IImu Kelautan UNSRAT. Vol. 7(3). Hal. 175-182

Kahar, M.G., J.N.W. Schaduw, Rumampuk N.D.C., W.E. Pelle, C. Sondakh, J. F.Pangemanan. 2020. Identifikasi sampah anorganik pada ekosistem mangrove desa talawaan bajo kecamatan wori kabupaten minahasa
Berdasarkan beberapa penelitian diatas, tingginya nilai bobot berat sampah anorganik ditentukan oleh banyaknya jumlah sampah perjenis, begitu pula sebaliknya jika jumlah sampah perjenis sedikit maka nilai bobot beratnya rendah. $\mathrm{Hal}$ ini diduga diakibatkan oleh adanya aktivitas masyarakat yang memberikan kontribusi masuknya makroplastik ke perairan melalui saluran air.

berat 17.51. Jumlah ukuran jenis sampah menunjukan bahwa terdapat 2 karakteristik yaitu mega-debris dan macro-debris dengan bobot total 514.37.

\section{Saran}

Berdasarkan hasil penelitian yang telah dilakukan di Desah Lesah maka disarankan perlu dilakukan penelitian pengaruh sampah terhadap organisme yang hidup di kawasan mangrove. Selain itu, banyaknya sampah yang ditemukan dalam penelitian ini dapat menjadi perhatian bagi pemerintah di Desa, masyarakat, LSM lingkungan maupun diri sendiri agar bisa menanganani sampah ke depannya. utara. Jurnal Pesisir dan Laut Tropis. Fakultas Perikanan dan IImu Kelautan UNSRAT. Vol 8 (1), Tahun 2020 Hal. 16

Lippiatt, S.M., Arthur, C.D., and Wallace, N.E. (2013). "Assessing the abundance and types of marine debris on shorelines and surface waters in Chesapeake Bay tributaries stratified by land use." Presentation at the Ocean Sciences Meeting, 20-24 February 2012, Salt Lake City, UT, USA. 
Mulana, F. (2016). Identifikasi Sampah Laut Di Kawasan Wisata Pantai Kota Makassar. Skripsi, 1-59.

NOAA [National Oceanic and Atmospheric Administration]. 2013. Programmatic Environmental Assessment (PEA) for the NOAA Marine Debris Program (MDP). Maryland (US): NOAA. $168 \mathrm{p}$.

NOAA. 2016. Marine Debris Program.

Patuwo, N.C., W.E. Pelle., H.W.K. Mangengkey., J.N.W. Schaduw., I.S.
Manembu., E. L. A. Ngangi. 2020. Karakteristik Sampah Laut di Pantai Tumpaan Desa Tatel Dua Kecamatan Mandolang Kabupaten Minahasa. Jurnal Pesisir dan Laut Tropis. Fakultas Perikanan dan IImu Kelautan UNSRAT. Vol. 8(1), Tahun 2020 Hal. 70-83

Salinding, A.R., Pusomah, J.H., Palar, N.A. 2016. Efektivitas Pengelolaan Sampah Oleh Dinas Kebersihan Dan Pertamanan Kota Manado. www.ejournal.unsrat.ac.id. Hal 1-12. 